\title{
Üniversite Öğrencilerinin Girişimcilik Niyetlerinin Betimlenmesine Yönelik Bir Yapısal Eşitlik Modeli Önerisi
}

Rana Şen DOĞAN*

Veysel YILMAZ ${ }^{* *}$

Geliş Tarihi (Received): 26.01.2017 - Kabul Tarihi (Accepted): 06.03.2017

\section{$\ddot{\mathbf{O z}}$}

Bir ülkenin ekonomik kalkınması ile büyümesinin, hızlandırılabilmesi ve sürdürülebilir olması için girişimcilik potansiyeline sahip bireylerin etkin olarak iş alanlarında yer alması büyük önem taşımaktadır. Girişimcilik potansiyelinin ortaya çıkartılmasında en önemli unsurların başında eğitim gelmektedir. Üniversite öğrencileri sözü edilen girişimcilik potansiyeline sahip olan bireylerden oluşmaktadır. Üniversite öğrencilerinin girişimci olma süreci, girişimci olmaya karar verdiklerinde başlar. Öğrencileri girişimciliğe teşvik etmek için, girişimciliği etkileyen faktörleri ortaya çıkararak girişimcilik kararına nasıl ulaştığını anlamak gerekir. Buna yönelik eğitimlerle öğrenciler girişimciliğe teşvik edilmeli ve geleceğin girişimci adayları topluma kazandırılmalıdır. Bu çalışmada üniversite öğrencilerinin demografik özellikleri ve girişimcilik niyetleri araştırılmaya çalışılmıştır. Başarı ihtiyacı, kontrol odağı, algılanan destek, algılanan engel gibi kişisel ve bağlamsal faktörler ile girişimciliğe yönelik tutum, algılanan davranışsal kontrol ve kişisel normun girişimcilik niyetlerinin üzerindeki etkisi önerilen bir Yapısal Eşitlik Modeli (YEM) arayıcılığıyla incelenmiştir. Sonuç olarak, girişimci adaylarına verilen girişimcilik eğitiminin arttırılması, doğru yönlendirmelerle iş hayatına kazandırılması, daha çok devlet desteği ile ekonomik yetersizliklerin giderilmesi ve bireylerin cesaretlendirilmesi önemli bulgular olarak değerlendirilmiştir.

Anahtar Kelimeler: Üniversite Öğrencileri, Girişimcilik, Girişimcilik Niyeti, Planlı Davranış Teorisi, Yapısal Eşitlik Modelleri

\footnotetext{
*Arş. Gör., Eskişehir Osmangazi Üniversitesi, Fen-Edebiyat Fakültesi, İstatistik Bölümü, ranasen07@ ogu.edu.tr

** Prof. Dr., Eskişehir Osmangazi Üniversitesi, Fen-Edebiyat Fakültesi, İstatistik Bölümü, vyilmaz@ogu.edu.tr
} 


\title{
A Proposal for a Structural Equation Model for the Representation of Entrepreneurial Intentions of University Students
}

\begin{abstract}
It is of great importance that individuals with an entrepreneurial potential are actively involved in their business areas in order to grow, accelerate and sustain the economic development of an country. Education is one of the most important elements in bringing out entrepreneurship potential. University students are made up of individuals who have the promised entrepreneurial potential. The process of university students becoming entrepreneurs starts when they decide to become entrepreneurs. In order to encourage entrepreneurship, students need to understand how entrepreneurship decisions are made by uncovering factors that affect entrepreneurship. Students should encourage entrepreneurship with this training and entrepreneurial candidates for the future should be encouraged. In this study, it was tried to investigate the demographic characteristics and entrepreneurial intentions of university students. Personal and contextual factors such as achievement needs, locus of control, perceived support, perceived barrier, and attitudes toward entrepreneurship, perceived behavioral control, and personal norms on entrepreneurial intentions were examined through a proposed Structural Equation Model (SEM). As a result, increasing entrepreneurship training for entrepreneur candidates, directing them towards business life, more government support and economic inadequacy, and encouragement of the individuals were considered important findings.
\end{abstract}

Keywords: University Student, Entrepreneurship, Intention of Entrepreneurship, Theory of Planned Behavior, Structural Equation Models 


\section{Giriş}

Ülkelerin ekonomik kalkınması ve büyümesi için girişimcilik potansiyeline sahip bireylere ihtiyacı vardır. Girişimcilik potansiyelinin ortaya çıkartılmasında en önemli unsurların başında eğitim gelmektedir. Girişimcilik eğitimi, ülkemizde "Uygulamalı Girişimcilik Eğitimleri” başlığı altında KOSGEB tarafından kısa dönemli eğitimler şeklinde verilmekte iken, üniversitelerde de seçmeli veya zorunlu dersler olarak okutulmakta, girişimcilik eğitim ve seminerleri düzenlenmektedir.

Girişimcilik eğitiminden beklenen amaç, bireylerde gizli kalmış, diğer bir ifadeyle ortaya çıkartılmayı bekleyen özelliklerin gün yüzüne çıkartılması, girişimcilik kültürünün yaygınlaştırılması ve girişimcilik potansiyeline sahip bireylerin cesaretlendirilmesidir. Üniversitelerde verilen girişimcilik eğitimleri ile öğrenciler, girişimcilikle ilgili eğilimleri altında yatan faktörlerin farkında olmakta ve bu farkındalık onların girişimciliğe yönlendirilmesinde büyük önem taşımaktadır (Balaban ve Özdemir, 2008).

KOSGEB gibi kurumlarca verilen eğitimlerde, bireyler artık girişimci olmaya karar vermiş ve bu yolda adım atmış olarak sayılmaktadırlar. Oysa üniversitelerde verilen eğitimlerde birey henüz girişimciliğe adım atmamış, fakat girişimcilik eğilimi oluşmaya başlamıştır. Bu sebeple bu çalışma, üniversite öğrencilerinin girişimcilik niyetini ölçmeye yöneliktir. Bu çalışmada Planlı Davranış Teorisi (PDT - TPB: Theory of Planned Behavior)'nden yararlanılarak üniversite öğrencilerinin girişimcilik niyetlerinin betimlenmesi için bir YEM önerilmiş ve önerilen bu model çeşitli uyum ölçütleri kullanılarak test edilmiştir.

Üniversite öğrencilerinin girişimci olma süreci, girişimci olmaya karar verdiklerinde başlar. Öğrencileri girişimciliğe teşvik etmek için, girişimciliği etkileyen faktörleri ortaya çıkararak girişimcilik kararına nasıl ulaştığını anlamak gerekir. Buna yönelik eğitimlerle öğrenciler girişimciliğe teşvik edilmeli ve geleceğin girişimci adayları topluma kazandırılmalıdır. Bu nedenle bu çalışmada girişimcilik niyetini etkileyen faktörler araştırılıp aralarındaki ilişkiler incelenmiştir. Öğrencilerin girişimcilik niyetlerini etkileyen başarı ihtiyacı, kontrolcü olma mekanizması, inanç ve düşüncesi, kısacası kişisel özellikleri gibi unsurların yanı sıra çevrenin desteği ve engeli konusundaki algısı ve karşısına çıkan bazı engel ve sorunlar da girişimciliğe yönelme konusunda bireyi etkileyen faktörlerdir (Çelik vd., 2014; Ermiş ve Barutçu, 2012).

$\mathrm{Bu}$ çalışma, girişimcilik konusunda olumsuz faktörlerin ve engellerin ortadan kaldırılması için gerekli önlemlerin alınmasına ve gerekli düzenlemelerin yapılmasına 1şık 
tutmasının yanı sıra, geleceğin girişimci adaylarının yetişmesi için de bir rehber niteliği taşıyacaktır.

$\mathrm{Bu}$ çalışmanın amac1, üniversite öğrencilerinin girişimcilik niyetleri araştırılırken, öğrencilerin girişimciliğe yönelme konusunda karşılaştı̆ğ sorunlardan aldığ 1 desteğe kadar girişimcilik niyetini etkileyen faktörleri araştırmaktır. Bu faktörler, kişisel norm, başarı ihtiyacı, kontrol odağı, algılanan destek, algılanan engel gibi bağlamsal faktörler ile girişimciliğe yönelik tutum ve algılanan davranış kontrolüdür. Bu faktörler arasındaki ilişkiler incelenerek girişimcilik niyetine etkileri araştırılacaktır. Böylece, girişimcilik ruhuna etki eden sosyopsikolojik ve sosyo-demografik unsurlar saptanarak, öğrencileri girişimciliğe teşvik edecek ipuçları elde edilmeye çalışılacaktır.

Arslan (2002), girişimcilik ruhunun kişide genetik olarak var olabileceği gibi ailesel faktörler, çevresel faktörler, gelir düzeyi ve eğitim gibi çeşitli unsurların da etkisiyle aktif hale gelebileceğini de söylemektir. Üniversite öğrencileriyle yapılan çalışmada, kişilerin girişimcilik eğilimlerinin oluşmasında ve buna yönelik meslek tercihlerinde fiziksel, sosyal ve ekonomik çevrenin rolü incelenmiş ve bu faktörlerin girişimcilik ruhunun gelişmesinde son derece önemli olduğu ortaya konmuştur.

Karabulut (2009), üniversite öğrencileriyle yaptı̆̆ çalışmada, girişimciliği, yaratıcılık, strese tahammül ve girişimcilik motivasyonu alt boyutları ile araştırmış fakat girişimciliğin sadece bu faktörlerle açıklanamayacağını belirtmiştir. Çalışmanın sonucunda, yaratıcılığı yüksek bireylerin, strese tahammülü olan ve girişimcilik motivasyonu yüksek olan öğrencilerden oluştuğu görülmüştür.

İbicioğlu vd. (2009), yaptıkları çalışmada, üniversite öğrencilerinin girişimcilik niyetleri ve sahip oldukları girişimcilik özellikleri üzerinde ailesel faktörlerin etkisini araştırmıştır. Anne babaların demografik özelliklerinin ve yaşam standartlarının bireylerin girişimcilik niyetleri ve girişimcilik özellikleri üzerinde etkili olduğu bulunmuştur. Ayrıca aileleri başarılı bir girişimcilik süreci geçirmiş öğrencilerin "risk alma” ve "kaynakları etkin kullanma” özelliklerine sahip olduğu gözlenmiştir.

Sommer ve Haug (2011), küçük ve orta ölçekli işletmelerde karar vericilerin niyetini etkileyen faktörleri açıklığa kavuşturmak için Planlı Davranış Teorisi kullanmıştır. Bu çalışmada, Planlı Davranış Teorisi'nin maddelerine ek olarak, tecrübe ve bilginin uluslararası girişimcilik niyetine etkisi araştırılmıştır. Sonuç olarak, Planlı Davranış Teorisi'nin iş 
dünyasına aktif olarak katılmak isteyenlerin niyetlerinin nasıl oluştuğunu açıklanmada gerçekten yardımcı olduğu görülmüş̧ür. Ayrıca bilgi ve tecrübenin de girişimcilik niyeti üzerinde anlamlı etkisinin olduğu gözlenmiştir. Öneri olarak, girişimciliği destekleyen politikaların geliştirilmesi gerektiği, saf kaynak tabanlı yaklaşımların yetersiz olduğu, girişimcilikle ilgili kurslarda ve müfredatta bilişsel yönlerin öneminin vurgulanması gerektiği söylenmiştir.

Bilge ve Bal (2011), üniversite öğrencilerinin girişimcilik konusundaki ilgilerini ve yeterliliklerini belirlemek için yaptığı çalışmada, risk alma, fiyatları değerlendirme, liderlik yönü, gelecek odağı, kararlılık ve dış etmenlere karşı bireysel güç olarak altı boyut oluşturmuş̧tur. Demografik özellikler incelendiğinde, cinsiyetin girişimciliğin tüm alt boyutları üzerindeki etkisi istatistiksel olarak anlamlı bulunmamıştır, fakat eğitimin girişimciliğin alt boyutlarından gelecek odağı ve liderlik yönü üzerindeki etkisi istatistiksel olarak anlamlı bulunmuştur.

Kalkan (2012), üniversite öğrencilerinde demografik özelliklerin, kişisel tutumunun, öznel normun ve algılanan davranış kontrolünün girişimcilik niyetine etkisini Planlı Davranış Teorisi yardımıyla araştırmıştır. Araştırma sonucunda, üniversite öğrencilerindeki kişisel tutumun algılanan davranışsal kontrolün girişimcilik niyeti üzerinde etkili olduğu görülmüş, fakat öznel normun girişimcilik niyeti üzerinde etkili olmadığı sonucuna ulaşılmıştır.

Uluköy vd. (2013), KOSGEB (Küçük ve orta ölçekli sanayi geliştirme ve destekleme idaresi) girişimcilik eğitimi kurslarına katılan katılımcıların girişimcilik özelliklerini ölçmüş ve alınan bu eğitimlerin katılımcılarda girişimcilik potansiyelini ortaya çıkarıp çıkarmadığını analiz ederek çözüm önerilerinde bulunmuştur. Araştırma sonucunda KOSGEB tarafından verilen girişimcilik eğitiminin girişimcilik bilincini oluşturmada önemli derecede katk1 sağladığı fakat uygulamada verilen girişimcilik eğitiminin başarı düzeyinin düşük olduğu sonucuna varılmıştır.

Mutlu (2014), Sivas'ta KOSGEB uygulamalı girişimcilik eğitim sertifikası kurslarına katılan kursiyerlerle yaptığı çalışma ile uygulamalı girişimcilik eğitim sertifikası kurslarına katılan girişimci adaylarının girişimcilik potansiyellerini, girişimciliğe bakışlarını, girişimci olma isteklerinin ardında yatan itici ve çekici nedenleri, girişimcilik planlarını ve girişimcilikte kursiyerlerin önünde gördüğü engellerin neler olduğunu tespit etmeyi amaçlamıştır. 
Obschonka vd. (2015), girişimcilik potansiyeline sahip bireylerin sahip olduğu özellikleri ve bunların girişimciliğe etkisini Planlı Davranış Teorisi ile açıklamıştır. Bir girişimcilik sürecini göz önüne alarak, girişimcilik öz kimliğinin belirleyicileri olarak girişimci kişilik yapısı, ergenlikte erken girişimcilik yeterliliği, geçmişteki girişimcilik davranışı ve kendi işini yapan ebeveynler dikkate alınmıştır. Daha sonra, girişimcilik öz kimliğinin Planlı Davranış Teorisi'nin maddeleri olan ve girişimcilik niyetini etkileyen tutum, kişisel norm ve algılanan davranışsal kontrol (girişimcilik niyetinin öngörücüleri) üzerinde etkili olup olmadığ1 araştırılmıştır. Sonuç olarak girişimcilik öz kimliğinin Planlı Davranış Teorisi'nin niyet öngörücülerini etkilediği ve dahası bu öngörücüler ile karakteristik bir moderatör etki gösterdiği bulunmuştur. Düşük kimlik seviyelerinde bu etkinin zayıf hatta sıfır olduğu gözlemlenmiştir. Aynı zamanda girişimcilik öz kimliğinin girişimcilik davranışı üzerinde etkili olup olmadığı incelenmiş ve davranış üzerinde doğrudan ya da dolaylı olarak etkisinin olmadığı görülmüştür.

Karimi vd. (2015), kişilik özellikleri, bağlamsal faktörler ve girişimcilik niyetleri arasındaki ilişkiyi test etmek için, Planlı Davranış Teorisi modeli ile iç kişilik faktörlerini ve dış bağlamsal faktörleri birleştirerek kavramsal bir model geliştirmiştir. Kişilik faktörleri olarak başarı ihtiyacı, risk alma ve kontrol odağı faktörlerini, bağlamsal faktörler olarak da algılanan engel ve algılanan destek faktörlerini ele almıştır. Çalışma İran'da üniversite öğrencilerine uygulanmış ve girişimcilik niyetinin birincil öngörücüleri olan Planlı Davranış Teorisi'nin maddeleri ile girişimcilik niyeti arasında anlamlı ilişkiler olduğu bulunmuştur. Bunlar arasında kişisel normun girişimcilik üzerindeki etkisinin daha önceki çakışmalara benzer olarak en düşük olduğu görülmüştür. Ayrıca, bağlamsal faktörlerin tutum üzerindeki etkilerinin ve bağlamsal faktörlerden algılanan desteğin girişimcilik niyeti üzerindeki etkisinin anlamsız olduğu gözlenmiştir. Dolayısıyla, girişimcilerin kariyer kararlarının başkalarının görüşünden etkilenmediği sonucuna ulaşmışlardır.

\section{1-Teorik Model (Arka plan) ve Hipotezler}

Sosyo-psikolojik araştırmalarda, davranışın gözlenmesi ve öngörülmesi zor olduğundan, planlanan bireysel davranışın en iyi öngörücüsü niyettir (Krueger vd., 2000; Karimi vd., 2015). Girişimcilik, planlı ve kasıtlı bir davranış olduğundan, girişimcilik davranışının öngörücüsü olarak da niyet ele alınmadır. Henüz girişimcilik davranışı sergilememiş bireylerin girişimcilik niyetlerini etkileyen faktörler belirlenerek bu bireylerin girişimcilik davranışı hakkında çıkarımlarda bulunulabilir. Uzun vadeli süreçte ise, girişimcilik niyetine sahip bireylerin girişimci olma yolunda atım attığı gözlemlenebilir. 
Girişimcilik niyeti, gelecekte sergilenecek olan girişimcilik davranışının bir numaralı öngörücüsü olarak söylenebilir (Kautonen, vd., 2015; Kolvereid ve Isakson, 2006; Karimi vd., 2015). Girişimcilik niyetini etkileyen diğer faktörler de dolaylı olarak girişimcilik davranışının öngörücüleridir. İlk araştırmalarda girişimcilik davranışının öngörücüleri olarak, sadece kişisel ve demografik özellikler dikkate alınmış ve sonrasında bunun yetersiz olduğu gözlemlenmiştir (Krueger vd., 2000; Karimi vd., 2015). Bunun üzerine araştırmacılar kapsamlı bilişsel modellere yönelmişlerdir. En yaygın olarak kullanılan model Planlı Davranış Teorisi (PDT) (Ajzen, 1991) modelidir. PDT ile belirli davranışların nasıl ve hangi amaçla ortaya çıktığı açıklanır. Ayrıca Ajzen (1991), PDT' nin uygunluğunun gösterilebilmesi ve test edilebilmesi koşuluyla başka yapılarla genişletilebileceğini de vurgulamıştır (Sommer ve Haug, 2011).

PDT modeli, davranışı gerçekleştirme niyetini veya mevcut durumda yeni girişim yaratmayı etkileyen üç motivasyonel önceliği vurgulamaktadır. (a) "Girişimciliğe Yönelik Tutum" yeni bir girişim başlatmanın olumlu ya da olumsuz olarak değerlendirilmesi şeklinde ifade edilebilir, (b) girişimci olmak ya da olmamak için sahip olunan "Kişisel Norm” ya da bir başka ifadeyle algılanan sosyal baskı ve (c) “Algılanan Davranışsal Kontrol” ya da girişimci olma algılanış kolaylığı / zorluğu (Karimi, 2015).

Girişimciliğe Yönelik Tutum (GYT), bireyin bir girişimci olma konusunda sahip olduğu olumlu ya da olumsuz kişisel bir değerleme derecesini ifade eder. Tutum sadece duygusal değil, aynı zamanda mantığa dayalı değerlendirilmiş düşünceleri de içerir (Liñán ve Chen, 2009, Kalkan, 2012).

Kişisel Norm (KN), girişimci davranışları yürütmek veya yürütmemek için algılanan sosyal baskıyı ölçer. Özellikle, referans kişilerin bir girişimci olma ya da olmama kararını destekledikleri algısını ifade eder. Toplumun değer ve normları girişimciliği önemli ölçüde etkilemektedir. Kişisel norm, kabul edilmiş inanç ve düşünceleri de ifade etmektedir (Park ve Blenkinsopp, 2009; Kalkan, 2012).

Algılanan Davranışsal Kontrol (ADK), bir girişimci olmanın zorluğunun veya kolaylığının algısı olarak tanımlanır. İlk olarak Bandura (1977) tarafından önerilen ADK, yetkinlik ve algılanan fizibilite ile oldukça benzer bir kavramdır. Son zamanda yapılan çalışmalarda, ADK ile algılanan fizibilite ve yetkinlik arasındaki fark vurgulanmış, ADK' nin hem yetkinliği hem de algılanan fizibiliteyi içerdiği için daha geniş kapsamlı bir kavram olduğu önerilmiştir. (Liñán ve Chen, 2009; Kalkan, 2012; Ajzen, 2002, Karimi vd., 2015). 
Girişimcilik niyeti üzerine yapılan daha önceki çalışmalarda, GYT, KN ve ADK'nin girişimcilik niyetini önemli derecede etkilediği bulunmuştur. (Iakovleva vd., 2011; Karimi vd., 2014; Krueger vd, 2000; Liñán ve Chen, 2009; Karimi vd., 2015; Sommer ve Haug (2011); Obschonka vd., 2015). Dolayısıyla, bu 3 faktörün öncülüğünde "Girişimcilik Niyeti (GN)" ni etkileyen faktörlerin bulunması ve aralarındaki ilişkilerin incelenmesi için aşağıdaki hipotezler önerilmiştir.

$H_{1}$ : (a) GYT, (b) KN ve (c) ADK, GN ile pozitif olarak ilişkilidir.

Planlı Davranış Teorisi'ne göre daha uzak fakat girişimcilikle bağlantılı olan "Başarı İhtiyacı (Bİ), Risk Alma Eğilimi (RA), Kontrol Odağ1 (KO)" gibi kişisel faktörler ile “Algılanan Destek (AD), Algılanan Engel (AE)” gibi bağlamsal faktörler, girişimcilik niyetini, direkt olarak ya da GYT ve ADK gibi faktörlere olan etkileri yoluyla dolaylı olarak etkilemektedir (Fishbein ve Ajzen, 2010, Karimi vd., 2015). Başarı ihtiyacı, risk alma eğilimi, kontrol odağı gibi kişisel özellikler, girişimcilik için bireylerin ihtiyaç duyduğu özelliklerdir. Daha önceki çalışmalarda bu özelliklerin girişimci kişiliğin bir parçası olduğu ve girişimcilik düzeyini etkilediği tespit edilmiştir. (Lüthje ve Franke, 2003; Rauch ve Frese, 2007; Robinson vd., 1991; Shaver ve Scott, 1991, Karimi vd., 2015).

Başarı ihtiyacı, zor işleri başarmayı seven, bir görevi diğer kişilerden daha iyi yapmaktan haz alan ve insanlar üzerinde otorite kurmaya eğilimli olan bireylerin kişilik özelliğidir. Risk alma eğilimi, bireylerin bir iş ya da çalışacak bir şirket seçerken risk alıp almama durumu, yüksek risk ve yüksek getiri sunan bir iş yerine düşük riskli ve sabit maaşlı bir iş seçip seçmeyeceği ve riskin kaçınılması gereken bir konu olup olmadığıyla ilgili düşünce ve tercihleriyle ilgilidir. Kontrol odağı ise, olayların bireyin kendi kontrolünde ya da dış güçlerin kontrolünde olduğuna dair algısıyla ilgilidir.

Bu bulgulara dayanarak, (a) Bİ, (b) RA ve (c) KO faktörlerinin GYT ve ADK ile ilişkili olduğu varsayılmış ve hipotezler aşağıdaki şekilde önerilmiştir.

$H_{2}$ : Bİ, (a) GYT ve (b) ADK ile pozitif olarak ilişkilidir.

$H_{3}$ : KO, (a) GYT ve (b) ADK ile pozitif olarak ilişkilidir.

Kişisel faktörlerin yanı sıra, çevresel ve bağlamsal faktörlerin de girişimcilik gibi bireysel ekonomik davranışlarda önemli rol oynadığı varsayılmaktadır. (North, 2005). Bağlamsal faktörler, girişimci isteklerini, niyetleri, fırsatları, faaliyetleri ve giriş oranlarını 
tanımlayabilir, yaratabilir, kolaylaştırabilir veya sınırlandırabilir (ör. Lüthje ve Franke, 2003, Karimi, 2015).

Algılanan destek, toplumda girişimciliğe olan pozitif alg1, şirket kurmak için danışmanlık hizmetlerinin yeterli olduğu algısı ve üniversitelerin iş fikri üretme konusundaki destekleri şeklinde ortaya çıkan dışsal faktörlerdir. Algılanan engel ise, yasa ve yönetmeliklerin şirket kurmayı zorlaştırdığ 1 , daha önce keşfedilmemiş bir iş fikri bulmanın ve yeni bir şirket kurmak için kredi almanın zorluğu gibi kişilerin iş kurma konusundaki engel algılarından oluşmaktadır.

Bu bulgulara dayanarak, (a) Bİ, (b) RA ve (c) KO faktörlerinin GYT ve ADK ile ilişkili olduğu varsayılmış ve hipotezler aşağıdaki şekilde önerilmiştir.

$H_{4}$ : Algılanan destek, (a) GYT, (b) ADK ve (c) Girişimcilik Niyeti ile pozitif olarak ilişkilidir. $H_{5}$ : Algılanan engel, (a) GYT ve (b) Girişimcilik Niyeti ile negatif olarak ilişkilidir.

Bu çalışmada ele alınan model, bu bağlamsal faktörlerden AD ve AE, GN'ni doğrudan, Bİ, RA, KO, AD, AE faktörleri, GYT' ye olan etkileri yoluyla, Bİ, RA, KO, AD, ADK yoluyla GN'ni etkilemektedir. Buna göre yukarıdaki hipotezler ortaya çıkmıştır. Araştırma modeli ise Şekil 1'de verildiği gibidir.

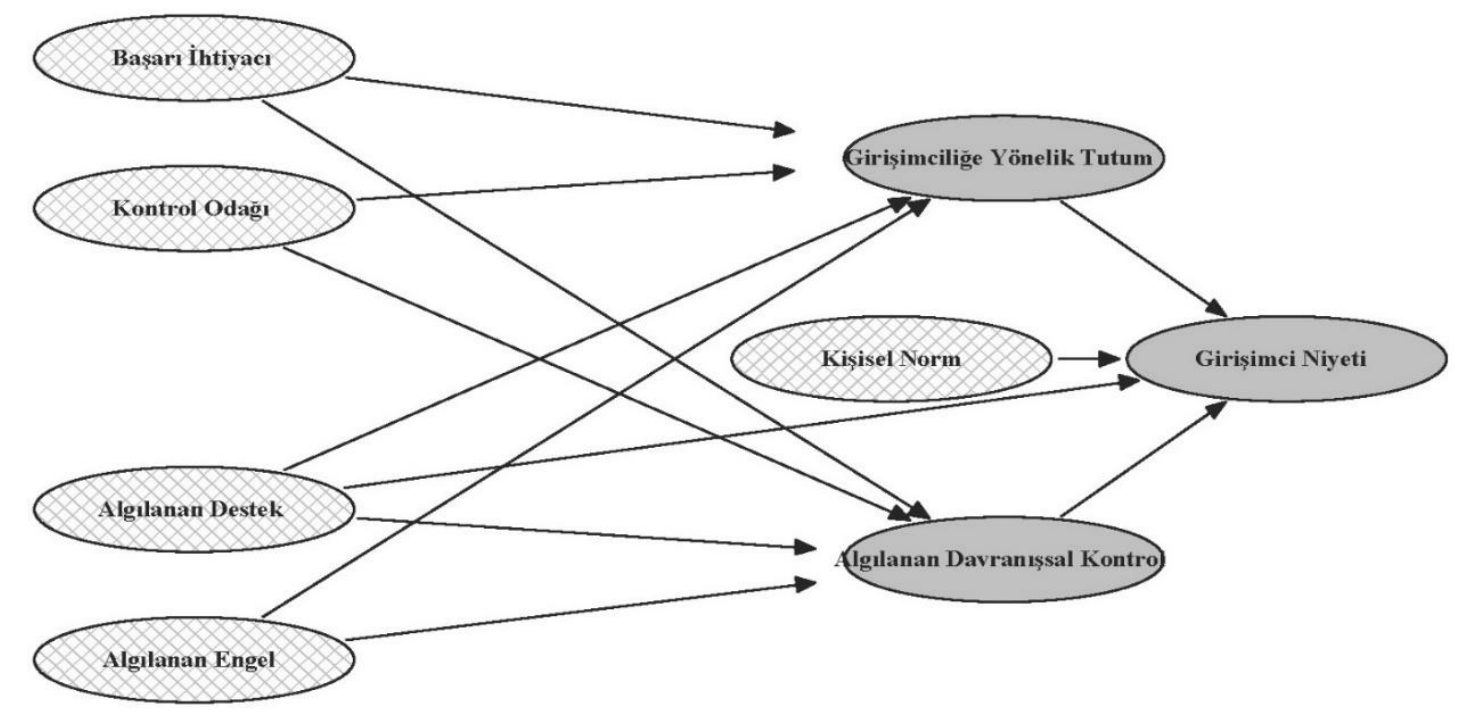

Şekil 1: Üniversite öğrencilerinin girişimcilik niyetleri için önerilen araştırma modeli 


\section{Yöntem}

\subsection{Veri Toplama Aracı}

Kullanılacak veri toplama aracı hazırlanmadan önce, girişimcilik niyetini etkileyen faktörlerin yer aldığı araştırmalar kapsamlı olarak incelenmiş ve Türkiye'de eğitim gören üniversite öğrencilerinin girişimcilik niyetlerini en iyi açıklayacağı öngörülen Karimi vd. (2015)'in çalışmasında yer alan modelden yola çıkarak araştırma modeli oluşturulmuştur. Araştırma modelinde PDT'nin faktörleri olan GN, KN, GYT, ADK ve bağlamsal faktörler olan $\mathrm{BI}, \mathrm{KO}, \mathrm{AD}$ ve $\mathrm{AE}$ 'nin maddeleri Türkiye şartlarına uyarlanmış ve anket soruları oluşturulmuştur. Karimi vd. (2015)'nin çalışmasında yer alan RA faktörüne pilot çalışmada yer verilmiş fakat varsayımların sağlanmasını engellediği için daha sonra modelden çıkarılmıştır.

Çalışma için hazırlanan anket formu birinci bölüm ve ikinci bölüm olmak üzere ikiye ayrılmıştır. Birinci bölümde kişinin, yaşı, cinsiyeti, öğrenim düzeyi, medeni durumu, anne babasının çalışma durumu gibi demografik bilgiler ve girişimciliğe bakış açısını ölçmek için, girişimcilikle ilgili eğitim düzeyleri, girişimcilik hakkındaki bazı düşünceleri, mesleki idealleri gibi sorular sorulmuştur. İkinci bölümde ise, 7'li likert tipi ölçek (1-Kesinlikle Katılmıyorum, 2-Katılmıyorum, 3-Biraz Katılmıyorum, 4-Ne Kat1lıyorum ne de Katılmıyorum, 5-Biraz Katılıyorum,6-Katılıyorum,7-Kesinlikle Katılıyorum) kullanılarak kullanıcıların girişimcilik niyetleri hakkındaki tutum, niyet ve kontrol davranışları ölçülmüştür. Anket yüz yüze görüşme yoluyla gerçekleştirilmiştir. Anketler içerisinde yanlış ve eksik doldurulmuş olan anketler analize dâhil edilmemiştir.

Anket çalışmasına başlamadan önce, anket sorularının güvenilirliğini test etmek için Eskişehir Osmangazi Üniversitesi öğrencilerinden oluşan 60 girişimci aday üzerinde pilot çalışma uygulanmıştır. Pilot çalışma sonucunda elde edilen verilerin güvenilirliği, SPSS 20 paket programı yardımıyla test edilmiştir. Test sonucunda Cronbach Alpha ( $\alpha$ ) değeri 0,89 olarak bulunmuştur. Alpha değeri 0.90'a çok yakın olduğu için anket sorularının oldukça güvenilir olduğu söylenebilir. Pilot çalışma esnasında adaylardan alınan geri bildirimler yardımıyla gerekli düzeltmeler yapılmış ve ankete son hali verilmiştir.

$\mathrm{Bu}$ çalışmanın evreni 2015-2016 eğitim öğretim yılında Eskişehir Osmangazi Üniversitesi'nde eğitim gören 19457 öğrenciden oluşmaktadır. Genel kabul gören olayın gerçekleşme olasılığı $\mathrm{p}=0,5$ ve gerçekleşmeme olasılı̆̆ 1 q=0,5 değerleri dikkate alındığında, \%95 güven aralığında ve \pm 0,05'lik sapma oranı ile örneklem sayısı hesaplandığında yaklaşık olarak 369 bulunmuştur. Örnekleme türü olarak tabakalı örnekleme yöntemi benimsenmiş, ana 
kütlenin tabakalara ayrılmasında kullanılan değişken ise fakülte olarak belirlenmiştir. Buna göre araştırma örneklemi, Eskişehir Osmangazi Üniversitesi’ndeki her bir fakülteden olasılıklı örnekleme yöntemiyle seçilmiş 369 öğrenciden oluşmaktadır.

Örneklemi oluşturan 369 bireyin demografik özelliklerine ilişkin özet bilgilere (cinsiyet, yaş, medeni durum, fakülte, baba çalışma durumu, anne çalışma durumu ve girişimcilik eğitimi alma durumu) Tablo 1'de yer verilmiştir.

Tablo 1: Tanımlayıcı İstatistikler

\begin{tabular}{|c|c|c|c|}
\hline Değişken & Gruplar & Frekans & Yüzde \\
\hline \multirow{2}{*}{ Cinsiyet } & Kadın & 178 & 48,2 \\
\hline & Erkek & 191 & 51,8 \\
\hline \multirow{3}{*}{ Yaş } & $18-24$ & 329 & 89,2 \\
\hline & $25-35$ & 39 & 10,6 \\
\hline & $36-45$ & 1 & 0,3 \\
\hline \multirow{2}{*}{ Medeni Durum } & Bekâr & 361 & 97,8 \\
\hline & Evli & 8 & 2,2 \\
\hline \multirow{6}{*}{ Fakülte } & Mühendislik & 133 & 36 \\
\hline & İİBF & 70 & 19 \\
\hline & ESYO & 18 & 4,9 \\
\hline & Eğitim & 48 & 13 \\
\hline & Fen Edebiyat & 81 & 22 \\
\hline & SHMYO & 19 & 5,1 \\
\hline \multirow{6}{*}{$\begin{array}{c}\text { Baba Çalışma } \\
\text { Durumu }\end{array}$} & Kamu Çalışanı & 68 & 18,4 \\
\hline & Özel Sektör Çalışanı & 77 & 20,9 \\
\hline & İşyeri Sahibi & 35 & 9,5 \\
\hline & Çalışmıyor & 13 & 3,5 \\
\hline & Emekli & 137 & 37,1 \\
\hline & Diğger & 39 & 10,6 \\
\hline \multirow{6}{*}{$\begin{array}{c}\text { Anne Çalışma } \\
\text { Durumu }\end{array}$} & Kamu Çalışanı & 30 & 8,1 \\
\hline & Özel Sektör Çalışanı & 44 & 11,9 \\
\hline & İşyeri Sahibi & 10 & 2,7 \\
\hline & Çalışmıyor & 241 & 65,3 \\
\hline & Emekli & 34 & 9,2 \\
\hline & Diğer & 10 & 2,7 \\
\hline Girişimcilik & Evet & 110 & 29,8 \\
\hline Eğitimi Alma & Hayır & 259 & 70,2 \\
\hline
\end{tabular}

\subsection{Yapısal Eşitlik Modelleri}

Çalışmada kapsamında kullanılacak yöntem Yapısal Eşitlik Modeli (YEM)’ dir. YEM, gözlenen değişkenler ile gizil değişkenler arasındaki nedensel ilişkilerin ve korelasyon ilişkilerinin bir arada bulunduğu modellerin test edilmesi için kullanılan çok değişkenli istatistiksel bir yöntemdir. YEM, önerilen teorik bir modelin sınanması ya da bu modelin hipotezlerinin test edilmesi temeline dayanmaktadır. Genellikle sonuçta birden fazla alternatif modelin karşılaştırılması yoluyla, veriyi en iyi tanımlayan modelin belirlenmesi amaçlanmaktadır (Çelik ve Yılmaz, 2013). 
YEM iki parçadan oluşmaktadır. Bunlardan birincisi, gözlenen değişkenleri gizil değişkenlere doğrulayıcı faktör analizi ile bağlanarak uygulanan ölçüm modeli; ikincisi ise birbirine eşzamanlı eşitlik sistemleri ile bağlanarak uygulanan yapısal modeldir $\mathrm{Bu}$ nedenle çalışmada kullanılan YEM için önce ölçüm modeli, ardından yapısal model iki aşamalı olarak LISREL 8.80 programı ile analiz edilmiştir. İlk aşamada, Doğrulayıcı Faktör Analizi (DFA) uygulanarak, faktör skorlarının geçerliliği, yakınsaklık geçerliliği ve ayırt edici geçerliliğe bakılarak ölçüm modeli incelenmiştir. İkinci aşamada ise YEM uygulanarak, yapılar arasındaki ilişkilerin kuvvetini ve yönünü araştırmak için yapısal model incelenmiştir. Fakat, YEM ile bir araştırma modelini test etmek için öncelikle YEM varsayımlarının sağlanması gerekmektedir. Söz konusu varsayımların bu çalışmada sağlanıp sağlanmadığı izleyen kısımda araştırılmıştır.

\section{Bulgular}

YEM analizinde, dikkat edilmesi gereken hususlardan biri eksik veri olup olmadığının belirlenmesidir. $\mathrm{Bu}$ çalışmada, eksik ve yanlış doldurulmuş anketler araştırmaya dâhil edilmediğinden, eksik veri olmadığı görülmüştür. Ayrıca, YEM varsayımlardan biri örneklem yeterliliğinin sağlanmasıdır. Bu çalışmada, parametrelerin doğru olarak tahmin edilebilmesi için LISREL paket programı aracılığıyla elde edilen minimum örneklem sayısı 223 olarak bulunduğundan, 369 olan örneklem sayısının yeterli olduğu söylenebilir. YEM' nin en önemli varsayımlarından biri olan çok değişkenli normallik varsayımı için, Mardia (1970) testine dayanarak, LISREL aracılığı ile yapılan çok değişkenli normallik testi sonucunda, Mardia Captcha değeri 1728 ve $p<0,001$ olarak bulunmuştur. Yani veri seti çok değişkenli normallik varsayımını sağlamamaktadır. Bu sebeple çalışmada parametre tahmin yöntemi olarak "Robust Maximum Likelihood" kullanılması uygun görülmüştür.

Ölçüm modelinin uyumu LISREL 8.80 kullanılarak test edilmiştir. Hesaplanan uyum ölçütleri yardımıyla modelin kabul edilebilir sınırlar içerisinde olduğu tespit edilmiştir $\left[\mathrm{X}^{2} / \mathrm{sd}=\right.$ 305/142 = 2,12 < 3,00 (Hayduk, 1987), Goodness of Fit Index (GFI) = 0,92>0,90 (Bagozzi and Yi, 1988), Adjusted Goodness of Fit Index (AGFI) = 0,89>0,8 (Scott, 1994), Normed Fit Index $(\mathrm{NFI})=0,96>0,9$ (Bentler and Bonett, 1980), Comparative Fit Index (CFI) = 0,98>0,9 (Bagozzi and Yi, 1988), Root Mean Square Error of Approximation $($ RMSEA) $=0,056<0,08$ (Bagozzi and $\mathrm{Yi}, 1988)]$.

Araştırma modeline ait faktörler, faktörlere ait yapı geçerliliği ve açıklanan varyans değerleri, standart yükler, $t$ değerleri, $\mathrm{R}^{2}$ değerleri ve Cronbach's Alpha değerleri Tablo 2'de verilmiştir. Yakınsaklık Geçerliliği’nin sağlanabilmesi için üç kriter söz konusudur. İlk olarak, 
gizil değişkenlere ait her bir gözlenen değişkenin standart faktör yükünün 0,5 ' den büyük olması ve istatistiksel olarak anlamlı olması gerekmektedir (Fornell ve Larcker, 1981). İkinci olarak, her bir yapı için Yapı Güvenilirliği (Composite Reliability - CR) ve Cronbach Alpha (CA) değerinin 0,7'den büyük olması gerekmektedir (Hair et al, 1998). Son olarak, her yap1 için Ortalama Açıklanan Varyans (Average Variance Extracted - AVE) değerinin 0,5'den yüksek olması gerekmektedir (Fornell ve Larcker, 1981). Bu çalışmada AD için AVE değeri 0,44 çıkmıştır fakat bu değer kabul edilebilirdir. Çünkü, Fornell ve Larcker (1981), CR değerinin 0,6'dan büyük olduğu durumda, AVE'nin 0,5'den küçük olmasının kabul edilebilir olduğunu ve yapı geçerliliğinin yeterli olduğunu ifade etmiştir (Huang vd., 2013). Çalışmanın yakınsaklık geçerliliği kontrol edildiğinde, standart faktör yüklerinin 0,59 ile 0,94 arasında değiştiği, CR ve CA değerlerinin ise 0,61 ve üstü değerler aldığı gözlenmiştir. AVE katsayılarından ikisi 0,50'nin altında iken diğerleri 0,50'nin üzerindedir. Bu nedenle yapıların yakınsaklık geçerliliği sağlanmıştır.

\section{Tablo 2:Araştırma Modeli için YEM Sonuçları}

\begin{tabular}{|c|c|c|c|c|}
\hline Faktörler / Maddeler & $\begin{array}{l}\text { Standart } \\
\text { Yükler }\end{array}$ & t-değeri & $\mathbf{R}^{2}$ & $\begin{array}{c}\text { Cronbach' } \\
\text { s Alpha }\end{array}$ \\
\hline Faktör GN: (Yapı geçerliliği: 0,89, Açıklanan varyans: 0,72) & & & & 0,87 \\
\hline GN1: Mesleki hedefim girişimci olmaktır. & 0,67 & $14,14 * * *$ & 0,44 & \\
\hline GN2: Ileride bir şirket kurma konusunda kararlıyım. & 0,94 & $23,33 * * *$ & 0,88 & \\
\hline GN3: Bir şirket kurmayı ciddi olarak düşünüyorum. & 0,92 & $22,49 * * *$ & 0,85 & \\
\hline Faktör GYT: (Yapı geçerliliği: 0,82, Açıklanan varyans: 0,60) & & & & 0,81 \\
\hline GYT1: Fırsatlar ve kaynaklara sahip olsam bir şirket kurmayı çok isterim. & 0,78 & $16,87 * * *$ & 0,61 & \\
\hline GYT2: Girişimci olmak beni tatmin edecektir. & 0,86 & $19,54 * * *$ & 0,75 & \\
\hline GYT3: Girişimci olmanın getirileri negatiften çok pozitiftir. & 0,67 & $13,72 * * *$ & 0,45 & \\
\hline Faktör KN: (Yapı geçerliliği: 0,88, Açıklanan varyans: 0,71) & & & & 0,88 \\
\hline KN1: Ailem girişimci olmam için beni destekler. & 0,77 & $16,77 * * *$ & 0,59 & \\
\hline KN2: Arkadaşlarım girişimci olmam için beni destekler. & 0,85 & $19,62 * * *$ & 0,73 & \\
\hline KN3: Görüşlerine değer verdiğim kişiler girişimci olmam için beni destekler. & 0,90 & $21,17 * * *$ & 0,81 & \\
\hline Faktör ADK: (Yapı geçerliliği: 0,80, Açıklanan varyans: 0,57) & & & & 0,79 \\
\hline ADK1: Yeni bir şirketin kurulum aşamasını kontrol edebilirim. & 0,64 & $12,56^{* * * *}$ & 0,40 & \\
\hline ADK2: Yeni iş fikirleri bulmak benim için kolay olacaktır. & 0,78 & $16,22 * * *$ & 0,61 & \\
\hline ADK3: Bir şirket kurmak ve onu ayakta tutmak benim için kolay olacaktır. & 0,84 & $17,87 * * *$ & 0,70 & \\
\hline Faktör Bi: (Yapı geçerliliği: 0,73, Açıklanan varyans: 0,58) & & & & 0,70 \\
\hline Bİ1: Bir görevi başka kişilerden daha iyi yapmak benim için önemlidir. & 0,87 & $14,77 * * *$ & 0,75 & \\
\hline B亡̈2: Diğer insanlar üzerinde otorite kurmak hoşuma gider. & 0,63 & $11,37 * * *$ & 0,40 & \\
\hline Faktör KO: (Yapı geçerliliği: 0,68, Açılklanan varyans: 0,52) & & & & 0,68 \\
\hline KO1: Hayatım kendi eylemlerim ile yön bulur. & 0,70 & $12,74 * * *$ & 0,49 & \\
\hline KO2: Hayatımda başarılı olup olmamam büyük oranda benim kabiliyetime bağlıdır. & 0,74 & $13,28 * * *$ & 0,54 & \\
\hline Faktör AD: (Yapı geçerliliği: 0,61, Açıklanan varyans: 0,44) & & & & 0,61 \\
\hline AD1: Yeni şirketler kurmak için danışmanlık hizmetleri yeterlidir. & 0,74 & $9,33 * * *$ & 0,54 & \\
\hline AD2: Üniversiteler yeni iş fikirleri üretme konusunda destek olurlar. & 0,66 & $8,34 * * *$ & 0,34 & \\
\hline Faktör AE: (Yapı geçerliliği: 0,66, Açıklanan varyans: 0,49) & & & & 0,66 \\
\hline AE1: Yeni şirket kurmak için bankalardan kredi almak kolay değil. & 0,51 & $9,41 * * *$ & 0,49 & \\
\hline AE2: Yasa ve yönetmelikler şirket kurmayı zorlaştırır. & 0,51 & $9,42 * * *$ & 0,50 & \\
\hline
\end{tabular}


Ölçüm modelinin ayırt edici geçerliliğinin sağlanması için her bir yapının AVE değerinin karekökünün, o yapı ile diğer yapılar arasındaki korelasyonunun karşılaştırılmasıyla kontrol edilir. Bu karşılaştırmalar sonucunda AVE’nin karekök değerleri daha büyük ise ayırt edici geçerlilik sağlanmış olur (Fornell ve Larcker, 1981). Tablo 3'de ölçüm modelinin ayırt edici geçerliliği verilmiştir. Buradan görüldüğü üzere, AVE’nin karekökü tüm yapılar için korelasyonlarından daha büyüktür. Dolayısıyla ayırt edici geçerlilik sağlanmış olur.

Tablo 3: Ayurt Edici Geçerlilik

\begin{tabular}{|c|c|c|c|c|c|c|c|c|}
\hline Yapılar & 1 & 2 & 3 & 4 & 5 & 6 & 7 & 8 \\
\hline 1. GN & 0,85 & & & & & & & \\
\hline 2. GYT & 0,69 & 0,77 & & & & & & \\
\hline 3. $K N$ & 0,45 & 0,67 & 0,84 & & & & & \\
\hline 4. $A D K$ & 0,64 & 0,53 & 0,43 & 0,75 & & & & \\
\hline 5. BI & 0,33 & 0,53 & 0,50 & 0,41 & 0,76 & & & \\
\hline 6. $\mathrm{KO}$ & 0,25 & 0,54 & 0,62 & 0,30 & 0,59 & 0,72 & & \\
\hline 7. $A D$ & 0,30 & 0,35 & 0,28 & 0,34 & 0,17 & 0,19 & 0,66 & \\
\hline 8. $A E$ & 0,15 & 0,19 & 0,31 & 0,21 & 0,25 & 0,28 & 0,42 & 0,70 \\
\hline$A V E$ & 0,72 & 0,60 & 0,71 & 0,57 & 0,58 & 0,52 & 0,44 & 0,49 \\
\hline
\end{tabular}

Not: Korelasyonlar arasindaki köşegen elemanlar AVE'nin kareköküdür. Tüm korelasyonlar $p<0,01$ 'de anlamlidir.

\subsection{Yapısal Model}

Bu çalışmada önerilen model, beş dişsal gizil değişken (Bİ, KO, $\mathrm{AD}, \mathrm{AE}, \mathrm{KN}$; $\mathrm{n}=5$ ) ve üç içsel gizil değişken (ADK, GYT, GN; m=3) den oluşmaktadır. YEM'de yapısal modellerin temel aldığg formül Eşitlik 1'deki gibi ifade edilebilir.

$$
\eta=B \eta+\Gamma \xi+\zeta
$$

Eşitlik 1'de, m: içsel gizil değişken sayısı, n: dışsal gizil değişken sayısı olmak üzere, $\eta$ : $m x 1$ boyutlu içsel gizil değişken vektörünü, $B: m x m$ boyutlu, ana diagonali sıfır olan boyutlu içsel gizil değişkenler arasındaki katsayılar matrisini, $\Gamma: m x n$ boyutlu içsel ve dışsal gizil değişkenler arasındaki katsayılar matrisini, $\xi: n x 1$ boyutlu dışsal gizil değişken vektörünü, $\zeta: m x 1$ boyutlu gizil hata terimleri vektörünü göstermektedir. 
Yapısal modele ait matris gösterimi ve yapısal denklemler ayırtılı olarak eşitlik 2 ve eşitlik 3'de ki gibi ifade edilebilir.

$$
\begin{aligned}
& {\left[\begin{array}{c}
\eta_{P B C} \\
\eta_{A T E} \\
\eta_{I E}
\end{array}\right]=\left[\begin{array}{ccc}
0 & 0 & 0 \\
0 & 0 & 0 \\
\beta_{I E, P B C} & \beta_{I E, A T E} & 0
\end{array}\right]\left[\begin{array}{c}
\eta_{P B C} \\
\eta_{A T E} \\
\eta_{I E}
\end{array}\right]+\left[\begin{array}{ccccc}
\gamma_{P B C, N A} & \gamma_{P B C, L C} & 0 & \gamma_{P B C, P S} & 0 \\
\gamma_{A T E, N A} & \gamma_{A T E, L C} & 0 & \gamma_{A T E, P S} & \gamma_{A T E, P B} \\
0 & 0 & \gamma_{I E, S N} & \gamma_{I E, P S} & \gamma_{I E, P B}
\end{array}\right]\left[\begin{array}{c}
\xi_{N A} \\
\xi_{L C} \\
\xi_{S N} \\
\xi_{P S} \\
\xi_{P B}
\end{array}\right]+\left[\begin{array}{c}
\zeta_{P B C} \\
\zeta_{A T E} \\
\zeta_{I E}
\end{array}\right]} \\
& \eta_{P B C}=\gamma_{P B C, N A} \cdot \xi_{N A}+\gamma_{P B C, L C} \cdot+\xi_{L C}+\gamma_{P B C, P S} \cdot \xi_{P S}+\zeta_{P B C} \\
& \eta_{A T E}=\gamma_{A T E, N A} \cdot \xi_{N A}+\gamma_{A T E, L C} \cdot+\xi_{L C}+\gamma_{A T E, P S} \cdot \xi_{P S}+\gamma_{A T E, P B} \cdot \xi_{P B}+\zeta_{A T E} \\
& \eta_{I E}=\beta_{I E P B C} \cdot \eta_{P B C}+\beta_{I E A T E} \cdot \eta_{A T E}+\gamma_{I E, S N} \cdot \xi_{S N}+\gamma_{I E, P S}+\xi_{P S}+\gamma_{I E, P B} \cdot \xi_{P B}+\zeta_{I E}
\end{aligned}
$$

YEM' de içsel gizil değişkenlere ait genel ölçüm model Eşitlik 4'deki gibi yazılır.

$$
y=\Lambda_{y} \cdot \eta+\varepsilon
$$

Eşitlik 4'te p içsel gizil değişkenlere ait toplam gözlenen değişken sayısı, y px1'lik içsel gizil değişkenlerin vektörü, $\Lambda_{y}$ içsel gizil değişkenler ile o içsel değişkenlere ait gözlenen değişkenler arasındaki ilişki, $\eta$ mx1'lik içsel gizil değişken vektörünü ve $\varepsilon$ px1'lik gözlenen değişkenlere ait hata vektörünü ifade eder.

Önerilen YEM'in içsel gizil değişkenlerin ölçüm modeline ait matris gösterimi ayırtılı olarak Eşitlik 5'de ki gibi ifade edilebilir.

$$
\left[\begin{array}{l}
y_{P C B 1} \\
y_{P C B 2} \\
y_{P C B 3} \\
y_{A T E 1} \\
y_{A T E 2} \\
y_{A T E 3} \\
y_{I E 1} \\
y_{I E 2} \\
y_{I E 3}
\end{array}\right]=\left[\begin{array}{lll}
\lambda_{P C B 1} & 0 & 0 \\
\lambda_{P C B 2} & 0 & 0 \\
\lambda_{P C B 3} & 0 & 0 \\
0 & \lambda_{A T E 1} & 0 \\
0 & \lambda_{A T E 2} & 0 \\
0 & \lambda_{A T E 3} & 0 \\
0 & 0 & \lambda_{I E 1} \\
0 & 0 & \lambda_{I E 2} \\
0 & 0 & \lambda_{I E 3}
\end{array}\right]\left[\begin{array}{c}
\varepsilon_{P C B 1} \\
\varepsilon_{P C B 2} \\
\varepsilon_{P C B 3} \\
\varepsilon_{A T E 1} \\
\varepsilon_{A T E 2} \\
\varepsilon_{A T E 3} \\
\varepsilon_{I E 1} \\
\varepsilon_{I E 2} \\
\varepsilon_{I E 3} \\
\eta_{I E E}
\end{array}\right]
$$

YEM'de dışsal gizil değişkenlere ait genel ölçüm modeli Eşitlik 6'deki gibi yazılır.

$$
x=\Lambda_{x} \cdot \xi+\delta
$$

Eşitlik 6'da q dışsal gizil değişkenlere ait toplam gözlenen değişken sayısı, x qx1'lik dışsal gizil değişkenlerin vektörü, $\Lambda_{x}$ dişsal gizil değişkenler ile o dişsal değişkenlere ait gözlenen değişkenler arasındaki ilişki, $\xi$ nxl'lik dışsal gizil değişken vektörünü ve $\delta$ qx1'lik gözlenen değişkenlere ait hata vektörüdür. 
Önerilen YEM'in dişsal gizil değişkenlerin ölçüm modeline ait matris gösterimi ayırtılı olarak Eşitlik 7'de ki gibi ifade edilebilir.

$$
\left[\begin{array}{l}
x_{N A 1} \\
x_{N A 2} \\
x_{L C 1} \\
x_{L C 2} \\
x_{S N 1} \\
x_{S N 2} \\
x_{S N 3} \\
x_{P S 1} \\
x_{P S 2} \\
x_{P B 1} \\
x_{P B 2}
\end{array}\right]=\left[\begin{array}{llllll}
\lambda_{N A 1} & 0 & 0 & 0 & 0 \\
\lambda_{N A 2} & 0 & 0 & 0 & 0 \\
0 & \lambda_{L C 1} & 0 & 0 & 0 \\
0 & \lambda_{L C 2} & 0 & 0 & 0 \\
0 & 0 & \lambda_{S N 1} & 0 & 0 \\
0 & 0 & \lambda_{S N 2} & 0 & 0 \\
0 & 0 & \lambda_{S N 3} & 0 & 0 \\
0 & 0 & 0 & \lambda_{P S 1} & 0 \\
0 & 0 & 0 & \lambda_{P S 2} & 0 \\
0 & 0 & 0 & 0 & \lambda_{P B 1} \\
0 & 0 & 0 & 0 & \lambda_{P B 2}
\end{array}\right]\left[\begin{array}{l}
\xi_{N A} \\
\xi_{L C} \\
\xi_{S N} \\
\xi_{P S} \\
\xi_{P B}
\end{array}\right]+\left[\begin{array}{l}
\delta_{N A 1} \\
\delta_{N A 2} \\
\delta_{L C 1} \\
\delta_{L C 2} \\
\delta_{S N 1} \\
\delta_{S N 2} \\
\delta_{S N 3} \\
\delta_{P S 1} \\
\delta_{P S 2} \\
\delta_{P B 1} \\
\delta_{P B 2}
\end{array}\right]
$$

Çalışma kapsamında araştırma modeli test edilmiş ve test sonucunda modelin kabul edilebilir sınırlar içinde olduğu görülmüştür $\left[\mathrm{X}^{2} / \mathrm{sd}=371 / 148=2,51<3,00\right.$ (Hayduk, 1987), GFI $=0,91>0,90$ (Bagozzi and Yi, 1988), AGFI $=0,87>0,8($ Scott, 1994), NFI $=0,95>0,9$ (Bentler and Bonett, 1980), CFI =0,97>0,9 (Bagozzi and Yi, 1988), RMSEA = 0,064<0,08 (Bagozzi and Yi, 1988)].

Modele ait path diyagramı ve standart yükler Şekil 2'de yer almaktadır. Aynı zamanda yapısal modelde her bir gizil değişkene ait yapısal denklemler ve açıklanma oranları Tablo 4'de verilmiştir.

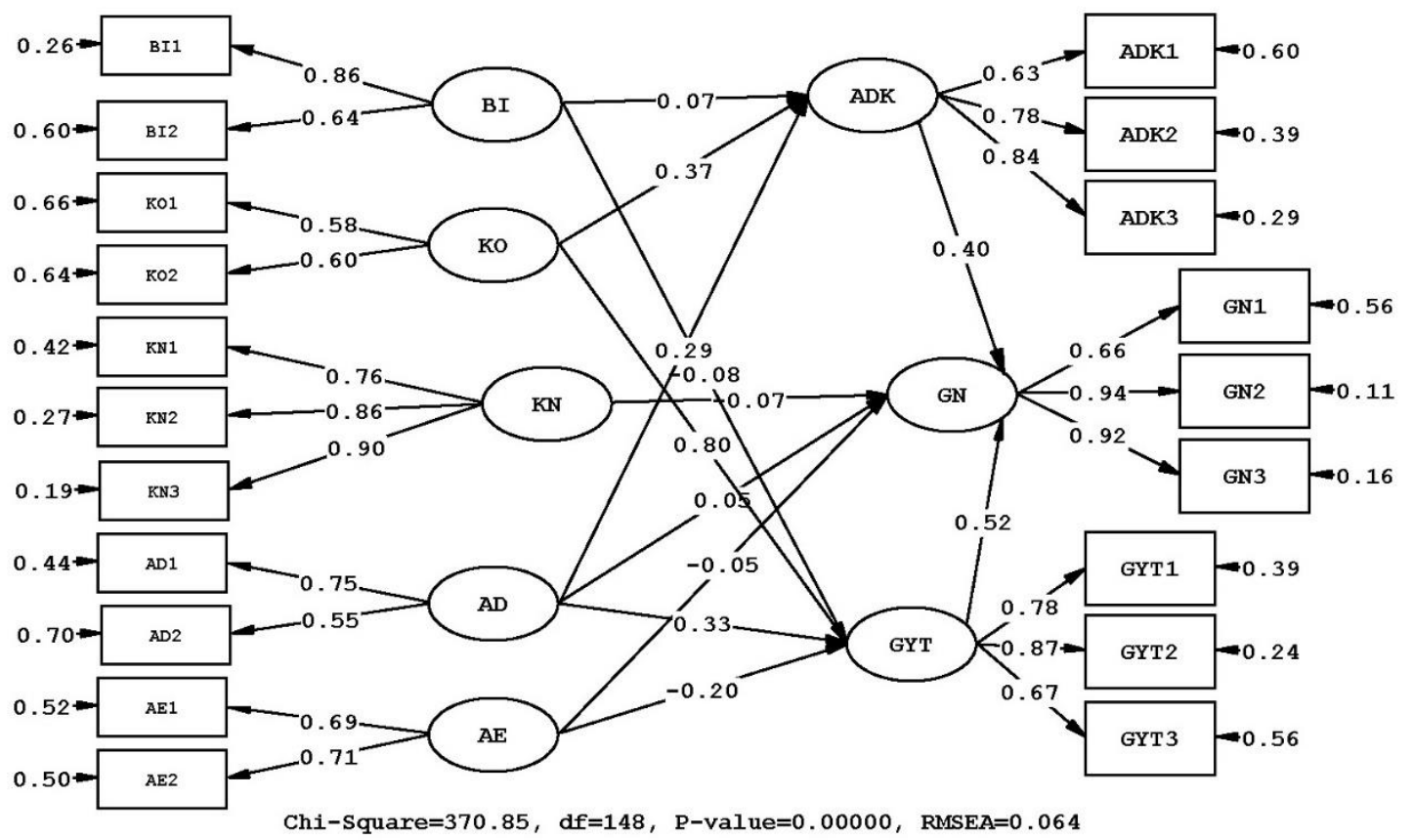

Şekil 2: Path Diyagramı 


\subsubsection{Hipotez Testi Sonuçları}

Tablo 1: Hipotezler ve Yapısal Eşitlikler

\begin{tabular}{|c|c|c|c|}
\hline Hipotezler & $\begin{array}{c}\text { Standart } \\
\text { Yükler }\end{array}$ & t-değeri & Sonuç \\
\hline$H_{l a}: G Y T \rightarrow G N$ & 0,50 & $6,83 * * *$ & Desteklendi \\
\hline$H_{1 b}: K N \rightarrow G N$ & $-0,07$ & $-1,06^{\mathrm{AD}}$ & Desteklenmedi \\
\hline$H_{l c}: A D K \rightarrow G N$ & 0,40 & $6,17 * * *$ & Desteklendi \\
\hline$H_{2 a}: B \dot{I} \rightarrow G Y T$ & $-0,08$ & $-0,67^{\mathrm{AD}}$ & Desteklenmedi \\
\hline$H_{2 b}: B \dot{I} \rightarrow A D K$ & 0,07 & $0,67^{\mathrm{AD}}$ & Desteklenmedi \\
\hline$H_{3 a}: K O \rightarrow G Y T$ & 0,80 & $6,47 * * *$ & Desteklendi \\
\hline$H_{3 b}: K O \rightarrow A D K$ & 0,37 & $3,39 * * *$ & Desteklendi \\
\hline$H_{4 a}: A D \rightarrow G Y T$ & 0,33 & $3,88 * * *$ & Desteklendi \\
\hline$H_{4 b}: A D \rightarrow A D K$ & 0,29 & $4,04 * * *$ & Desteklendi \\
\hline$H_{4 c}: A D \rightarrow G N$ & 0,05 & $0,73^{\mathrm{AD}}$ & Desteklenmedi \\
\hline$H_{5 a}: A E \rightarrow G Y T$ & $-0,20$ & $-2,26 * *$ & Desteklendi \\
\hline$H_{5 b:}: A E \rightarrow G N$ & $-0,05$ & $-0,80^{\mathrm{AD}}$ & Desteklenmedi \\
\hline \multicolumn{4}{|c|}{$\begin{array}{c}\mathrm{GN}=0.52 * \mathrm{GYT}+0.40 * \mathrm{ADK}-0.068 * \mathrm{KN}+0.047 * \mathrm{AD}-0.048 * \mathrm{AE}, \mathrm{R} 2=0.56 \\
\mathrm{GYT}=-0.081 * \mathrm{BI}+0.80 * \mathrm{KO}+0.33 * \mathrm{AD}-0.20 * \mathrm{AE}, \mathrm{R} 2=0.63 \\
\mathrm{ADK}=0.073 * \mathrm{BI}+0.37 * \mathrm{KO}+0.29 * \mathrm{AD}, \mathrm{R} 2=0.31\end{array}$} \\
\hline
\end{tabular}

Tablo 4 incelendiğinde, $H_{1 b}, H_{2 a}, H_{2 b}, H_{4 c}, H_{5 b}$ hipotezleri istatistiksel olarak anlaml olmadığı için desteklenmediği görülmektedir. Buna göre, bağlamsal faktörlerden Bİ ile ADK ve GYT arasında direkt olarak ilişki olmadığı görülmektedir. Aynı zamanda, KN, AD ve AE bağlamsal faktörleri ile GN arasında da direkt olarak ilişki bulunmamaktadır.

Buna karş1l1k $H_{l a}, H_{1 c}, H_{3 a}, H_{3 b}, H_{4 a}, H_{4 b}$ ve $H_{5 a}$ hipotezleri $\% 5$ anlamlılık düzeyinde istatistiksel olarak desteklenmiştir. KO ile ADK arasında pozitif yönlü ve 0,37 birimlik ilişki söz konusudur. Bu demek oluyor ki, KO değişkenindeki bir birimlik artış ADK üzerinde 0,37 birimlik artışa sebep olmaktadır. Benzer şekilde, AD ile ADK arasında pozitif yönlü ve 0,29 birimlik ilişki, KO ile GYT arasında pozitif yönlü ve 0,80 birimlik ilişki, AD ile GYT arasında pozitif yönlü ve 0,33 birimlik ilişki söz konusudur. Benzer şekilde yorumlanabilir.

AE ile GYT arasında ise negatif yönlü ve 0,20 birimlik ilişki söz konusudur. Böylece, AE değişkenindeki bir birimlik artış GYT değişkeninde 0,20 birimlik azalışa sebep olmaktadır.

ADK ile GN arasında pozitif yönlü ve 0,40 birimlik ilişki, GYT ile GN arasında ise pozitif yönlü ve 0,50 birimlik bir ilişki söz konusudur.

\section{Tartışma ve Sonuç}

Girişimcilik konusundaki çalışmaların çoğu, girişimciler, daha doğrusu girişimciliğe başlayan veya bu konuda belirli bir yol kat eden kişiler arasında yapılmıştır. Bu açıdan bakıldığında, potansiyel girişimci adayları arasındaki araştırmaların sınırlı olduğu 
görülmektedir. $\mathrm{Bu}$ nedenle, bu çalışmada potansiyel girişimci olarak görülen üniversite öğrencilerinin girişimcilik niyetlerini etkileyen faktörler incelenmiş, kişisel ve bağlamsal faktörlerin üniversite öğrencilerinin girişimcilik niyetlerini belirlemedeki rolü planlı davranış teorisi yardımıyla önerilen bir YEM ile araştırılmıştır. Bulguların kişisel ve bağlamsal faktörlerin girişimcilik niyetinin belirlenmesi için uygun olan planlı davranış teorisi modeline entegre edilebileceği ve bu faktörlerin girişimcilik niyetinin öngörücüleri olan tutum ve davranış kontrolü değişkenlerindeki etkilerinin göz ardı edilemeyeceği gözlenmiştir.

Kişisel faktörlerden, KO faktörünün GYT ve ADK faktörlerini pozitif ve önemli derecede etkilediği, buna karşılık Bİ faktörünün, bu faktörler üzerinde etkili olmadığ1 görülmüştür. Burada üniversite öğrencilerinin yaşlarının genç olması, henüz iş tecrübesi kazanmamış olması ve gelecek kaygısı taşımamaları dolayısıyla başarı ihtiyacı kişilik özelliğinin henüz gelişmemiş olmasının etkin rol oynamış olduğu düşünülebilir. Kontrol odağ1 ise, kendine güvenen bireylerde ortaya çıkan bir kişilik özelliği olduğu için, bu kişilerde girişimcilik tutumunun ve davranış kontrolünün yüksek olması beklenen bir durumdur. KO faktörünün, özellikle ADK ile çok yüksek ilişkili çıkması, bu faktörün modelde yer almasının önemini göstermektedir.

Bağlamsal faktörlerden, AD faktörünün, GYT ve ADK faktörleriyle ilişkisinin yanı sıra, GN ile doğrudan ilişkisinin olup olmadığı incelenmiş ve bu faktörün GN ile doğrudan ilişkisi olmadığı, fakat GYT ve ADK faktörleri yardımıyla GN faktörünü etkilediği görülmüştür. Sonuç olarak, bireylerin destek algısının gelişmesinin girişimcilik tutumunu ve davranış kontrolünü arttırdığı ve dolayısıyla girişimcilik niyetini arttırdığ1 söylenebilir. Bireylere üniversitelerde verilen eğitimlerle destek algısının arttırılması mümkündür ve bu sayede eğitimin girişimcilik niyetinin oluşmasında önemli rol oynadığı söylenebilir. Burada AD'in GN üzerindeki doğrudan etkisinin anlamlı olmaması dikkat çekmektedir. Böylece, GN'nin birincil tahmincileri olan GYT ve ADK faktörlerinin, girişimcilik niyetini ortaya çıkarmada ne kadar önemli olduğu görülmektedir.

Bağlamsal faktörlerden AE faktörünün, GYT ve GN üzerindeki etkisi incelenmiş ve GYT faktörünü negatif olarak etkilediği fakat GN'ni doğrudan etkilemediği gözlenmiştir. AE de, AD gibi GN'ni doğrudan değil dolaylı olarak etkilemektedir. Engel algısının artması sonucunda bireylerde girişimcilik tutumunun azalması ve dolayısıyla girişimcilik niyetinin azalması söz konusudur. Bu algının ortadan kaldırılabilmesi için girişimcilik eğitiminin önemli 
bir rol oynadığı bir kez daha ortaya çıkmaktadır. Girişimcilik eğitimlerinde bireylere, değerli fikirlere sahip projelerin finansal olarak desteklenmesinin zor olmadığg vurgulanabilir.

KN, Planlı Davranış Teorisi'nin faktörlerinden olduğu için girişimcilik niyetini etkilediği varsayılmış, fakat analiz sonucunda girişimcilik niyetini etkilemediği görülmüştür. Bunun sebebi, üniversite öğrencisi olan bireylerin, henüz girişimcilik davranışında bulunmamış olması ve dolayısıyla aile, arkadaş ve görüşlerine değer verdiği kişilerin henüz görüşlerini almamış olmasının etkisi olabileceği gibi bu kişilerin görüşlerinin bireyin girişimcilik niyetini gerçekten etkilememesi de olabilir. Bunun için girişimcilik davranışını sergilemiş bireyler üzerinde yapılacak çalışmalarla, bu faktörün girişimcilik niyeti üzerindeki etkisi incelenebilir.

Planlı Davranış Teorisi'nin diğer faktörleri olan GYT ve ADK, öngörüldüğü üzere girişimcilik niyetini önemli derecede etkilemektedir. Bireylerin tutum ve davranış kontrollerinin girişimcilik niyetini geliştirmesi, girişimcilik niyetini en üst düzeye çıkarmak için bu motivasyonel faktörlerin desteklenmesine önem verilmesi gerektiğini göstermektedir. Bunun için algılanan davranış kontrolünü iyileştirmek ve girişimcilik üzerine olumlu tutum gerçekleştirmek için çeşitli yöntemler araştırılmalı ve girişimcilik eğitimlerinde bu yöntemlerin uygulanabileceği değerlendirilmelidir.

Sonuç olarak, girişimci adaylarına verilen girişimcilik eğitiminin arttırılması, doğru yönlendirmelerle iş hayatına kazandırılması, daha çok devlet desteği ile ekonomik yetersizliklerin giderilmesi ve bireylerin cesaretlendirilmesi önerilmektedir.

\section{Kaynakça}

Ajzen, I. (1991). The theory of planned behaviour. Organizational Behavior and Human Decision Processes, 50(2), 179-211.

Ajzen, I. (2002). Perceived behavioral control, self-efficacy, locus of control, and the theory of planned behavior. Journal of Applied Social Psychology, 32(4), 665-683.

Arslan, K. (2002). Üniversiteli gençlerde mesleki tercihler ve girişimcilik eğilimleri. Doğuş Üniversitesi Dergisi, $6,1-11$.

Balaban, Ö. ve Özdemir, Y. (2008). Girişimcilik eğitiminin girişimcilik eğilimi üzerindeki etkisi: Sakarya Üniversitesi İİB örneği. Girişimcilik ve Kalkınma Dergisi, 3(2), 133-147.

Bandura, A. (1977). Social learning theory. Englewood Cliffs, NJ: Prentice-Hall.

Bagozzi, R.P. and Yi, Y. (1988). On the evaluation of structural equation models. Journal of the Academy of Marketing Science, 16(1), 74-94.

Bentler, P.M. and Bonett, D.G. (1980). Significance tests and goodness of fit in the analysis of covariance structures. Psychological bulletin, 88(3), 588-606.

Bilge, H. ve Bal, V. (2011). Girişimcilik eğilimi: Celal Bayar Üniversitesi öğrencileri üzerine bir araştırma. Süleyman Demirel Üniversitesi Sosyal Bilimler Enstitüsü Dergisi,16(2), 131-148. 
Çelik A., İnce M. ve Bozyiğit S. (2014). Üniversite öğrencilerinin girişimcilik niyetlerini etkileyen ailesel faktörleri belirlemeye yönelik bir çalışma. Niğde Üniversitesi İktisadi ve İdari Bilimler Fakültesi Dergisi, 7(3), $113-124$.

Çelik, E. H. ve Yılmaz, V. (2013). LISREL 9.1 ile Yapısal Eşitlik Modellemesi, Temel kavramlar-uygulamalarprogramlama. Anı Yayıncilık, Ankara.

Ermiş, A. ve Barutçu, E. (2012). Öğrencilerin kendilerini girişimci bir kişiliğe sahip görmelerini ve iş kurma niyetlerini etkileyen faktörler: bir alan araştırması. Atatürk Üniversitesi Ikktisadi ve İdari Bilimler Dergisi, Cilt: $26(2), 1-25$.

Fishbein, M. and Ajzen, I. (2010). Predicting and changing behavior: The reasoned action approach. New York, NY: Psychology Press.

Fornell, C. and Larcker, D. F. (1981). Evaluating structural equation models with unobservable variables and measurement error. Journal of marketing research, pp. 39-50.

Hayduk. L. (1987). Structural equation modeling with LISREL: essentials and advances. Baltimore: Johns Hopkins University Press.

Huang, C.-C. and Wang, Y.-M. and Wu, T.-W., and Wang, P.-A. (2013, April). An Empirical Analysis of the Antecedents and Performance Consequences of Using the Moodle Platform. International Journal of Information and Education Technology, 3(2). doi: 10.7763/IJIET.2013.V3.267.

Iakovleva, T., Kolvereid, L., and Stephan, U. (2011). Entrepreneurial intentions in developing and developed countries. Education+Training, 53(5), 353-370.

İbicioğlu, H., Özdaşl1, K. ve Alparslan, A.M. (2009). Girişimcilik özellikleri ve girişimcilik kültürü tercihi üzerinde ebeveyn etkisi: Mehmet Akif Ersoy Üniversitesi araştırması. Selçuk Üniversitesi Sosyal Bilimler MYO Dergisi, 12(1-2), 521-538.

Kalkan, A. (2012). Kişisel tutum, öznel norm ve algılanan davranış kontrolünün girişimcilik niyeti üzerindeki etkisi: üniversite öğrencileri üzerine bir uygulama, Süleyman Demirel Üniversitesi Sosyal Bilimler Enstitüsü Dergisi, 2(14).

Karabulut, A.T. (2009). Üniversite Öğrencilerinin Girişimcilik Özelliklerini Ve Eğilimlerini Belirlemeye Yönelik Bir Araştırma. Marmara Üniversitesi İIBF Dergisi, 16(1), 331-356.

Karimi, S., Biemans, H. J. A., Lans, T., Chizari, M., \& Mulder, M. (2014). Effects of role models and gender on students' entrepreneurial intentions. European Journal of Training and Development, 38(8), 694-727.

Karimi, S., Biemans, H. J. A., Mahdei, K.N., Lans, T., Chizari, M. and Mulder, M. (2015). Testing the relationship between personality characteristics, contextual factors and entrepreneurial intentions in a developing country, International Journal of Psychology, doi: 10.1002/ijop.12209

Kautonen, T., van Gelderen, M., and Fink, M. (2015). Robustness of the theory of planned behavior in predicting entrepreneurial intentions and actions. Entrepreneurship: Theory and Practice, 39(3), 655-674.

Krueger, N. F., Reilly, M. D. and Carsrud, A. L. (2000). Competing models of entrepreneurial intentions. Journal of Business Venturing, 15(5-6), 411-432.

Kolvereid, L. and Isakson, E. (2006). New business start-up and subsequent entry into self-employment. Journal of Business Venturing, 21(6), 866-885.

Liñán, F., \& Chen, Y.-W. (2009). Development and cross-cultural application of a specific instrument to measure entrepreneurial intentions. Entrepreneurship Theory and Practice, 33(3), 593-617.

Lüthje, C., and Franke, N. (2003). The 'making' of an entrepreneur: Testing a model of entrepreneurial intent among engineering students at MIT. R\&D Management, 33(2), 135-147.

Mardia, K.V. (1970). Measures of multivariate skewness and kurtosis with applications. Biometrika, 57, 519-530. 
Mutlu, S. (2014). KOSGEB'in uygulamalı girişimcilik sertifikası eğitimi kurslarına katılan kursiyerlerin girişimcilik potansiyelleri ve eğilimleri. Girişimcilik ve Kalkınma Dergisi 9(1), 2-22.

North, D. C. (2005). Understanding the process of economic change. Princeton, NJ: Princeton University Press.

Obschonka, M., Silbereisen, R. K., Cantner, U. and Goethner, M. (2015). Entrepreneurial self-1dentity: predictors and effects within the theory of planned behavior framework, J Bus Psychol, 30(4), 773-794, doi: 10.1007/s10869014-9385-2

Park, H. and Blenkinsopp J. (2009). Whistleblowing as planned behavior -a survey of South Korean police officers. Journal of Business Ethics, 85(4), 545-556, doi: 10.1007/s10551-008-9788-y

Rauch, A., and Frese, M. (2007). Let's put the person back into entrepreneurship research: a meta-analysis of the relationship between business owners' personality characteristics and business creation and success. European Journal of Work and Organizational Psychology, 16(4), 353-385.

Robinson, P. B., Stimpson, D. V., Huefner, J. C., and Hunt, H. K. (1991). An attitude approach to the prediction of entrepreneurship. Entrepreneurship Theory and Practice, 15(4), 13-31.

Scott, J.E. (1995). The measurement of information systems effectiveness: evaluating a measuring instrument. ACM SIGMIS Database, 26(1):43-61.

Shaver, K. G., and Scott, L. R. (1991). Person, process, choice: The psychology of new venture creation. Entrepreneurship: Theory and Practice, 16(4), 23-44.

Sommer, L, and Haug, M. (2011). Intention as a cognitive antecedent to international entrepreneurship understanding the moderating roles of knowledge and experience. Int Entrep Manag J, 7, 111-142.

Uluköy, M., Demireli, C. ve Kahya, V. (2013). KOSGEB Girişimcilik Eğitim Kurslarına Katılan Katılımcıların Girişimcilik Profiline Yönelik Bir Alan Araştırması, Girişimcilik ve Kalkınma Dergisi (8)2. 